\title{
SPLANCHNIC CIRCULATION IN SMALL FOR DATE NEWBORNS
}

\author{
Paulusova E, Stillova L, Haskova K, Matasova K.
}

Clinic of Neonatology, Jessenius Faculty of Medicine, Comenius University and University Hospital in Martin, Slovakia

\section{A b s t r a c t}

Hypotrophic newborn is a newborn with birth weight below the 5th percentile weight of corresponding gestational age. Hypotrophic infants have higher morbidity and mortality in comparison with eutrophic neonates. A higher incidence of hypoglycemia, polycythemia, hyperbilirubinemia, thrombocytopenia, perinatal asphyxia and caesarean section occurs typically in hypotrophic newborns. Both, intrauterine hemodynamic dysbalance and centralization of circulation due to hypotrophy cause decreased blood flow to the splanchnic circulation after the birth. There was observed a lower increase in blood flow through the coeliac artery and superior mesenteric artery in comparison with eutrophic newborns during the first postnatal week. These facts are likely to be associated with a higher frequency of abdominal problems and necrotizing enterocolitis.

Key words: small for date newborn, splanchnic circulation, necrotizing enterocolitis

\section{INTRODUCTION}

Hypotrophic newborn is defined as a newborn with birth weight below the 5th, eventually below the 10th percentile of weight for corresponding gestational age. More precise definitions are based on birth length and birth weight, or eventually also on head and chest circumference in association with thickness of subcutaneous fat.

An equivalent term for "hypotrophic" newborn is "small for date" (or small for gestational age - SGA). This term is often mistakenly associated with growth restricted fetus (or intrauterine growth restriction - IUGR). The mentioned terms are not synonymous. Growth restricted fetus is defined as „a fetus that fails to reach his potential growth“, on the other hand SGA is a different entity, and is defined as a newborn with birth weight below a given (usually) the $10^{\text {th }}$ percentile for gestational age. The term IUGR should be used only in regard to the fetus whereas SGA should be used mainly in the newborn (but it can be estimated from sonographic measurement of the fetus) (1).

According to the etiopathogenesis, hypotrophy is either symmetric (proportional), asymmetric (disproportional) and combined. If a causative factor is present in early stages of pregnancy and affects cell growth in the stage of hyperplasia, or if it is present during a long period of pregnancy, symmetrical hypotrophy occurs. There is not only reduced birth weight in such infants, but also head circumference, body length and size of body organs are reduced. The causal factors include genetic anomalies, congenital infections and congenital malformations. If the causative factor is active later during pregnancy, when cell growth is mainly caused by hypertrophy, or if it is present during a short period of pregnancy, asymmetric hypotrophy occurs. Then both, body weight and a layer of subcutaneous fat are decreased. Uteroplacental insufficiency and inadequate maternal nutrition during the third trimester of pregnancy are the most frequent causes of asymmetric hypotrophy (2).

Factors causing hypotrophy are generally accepted as a risk factor of neonatal and maternal morbidity and mortality. Morbidity and mortality in hypotrophic infants are higher in

\footnotetext{
Ad dress for correspondence:

Eva Paulusova, MD, Clinic of Neonatology, Jessenius Faculty of Medicine, University Hospital Martin, Kollarova 2, 036 01, Martin, Slovak Republic, Phone:+421043/4203 641;

e-mail: eva.paulusova@post.sk
} 
comparison with eutrophic newborns. Conditions such as hypoglycemia, polycythemia, thrombocytopenia, perinatal asphyxia and hyperbilirubinemia are more common in hypotrophic newborns. Failure of splanchnic blood flow, which is due to intrauterine centralization of circulation and persists postnatally, is likely to cause more frequent occurrence of enteral feeding intolerance and necrotizing enterocolitis.

\section{CIRCULATION IN EUTROPHIC AND HYPOTROPHIC NEWBORNS}

Factors leading to hypotrophy, cause that fetal blood is redistributed to the brain, heart and adrenal glands. At the same time, the blood flow through kidneys, gastrointestinal tract, liver, lung and spleen decreases. If the end - diastolic part of blood flow in uterine artery does not increase gradually during the course of pregnancy, or if there is a little notch in blood flow curves at the end of systole, fetal hypotrophy may be predicted with high probability (70-90\%) (3).

The aim of the centralization of circulation is to ensure blood supply to the vital organs such as the brain, heart and adrenal glands, and this is called brain sparing phenomenon, as it was mentioned in the work by Hernandez-Andrade et al., (2008). The authors described an increase in blood flow velocity in different parts of brain according to the seriousness of fetal growth restriction. (4).

Mari et al. in 1995 compared the hemodynamic parameters in the splenic artery, superior mesenteric artery and renal artery in eutrophic and hypotrophic fetuses. The lowest values of pulsatility index, which characterizes the resistence of vascular bed after the point of measuring blood flow, have been reported in the splenic artery in the eutrophic and hypotrophic fetuses. The hypotrophic fetuses have lower pulsatility index in the superior mesenteric artery compared with the renal artery, while the pulsatility indices in these vessels of eutrophic fetuses are not significantly different. Therefore, the blood supply to the gastrointestinal tract of a hypotrohic fetus is preferred to the blood supply to fetal kidney (5). Korszun et al., (2002) study has not confirmed the conclusions of Mari's work, (1995). His results indicate that the majority of fetuses (83.3\%) from risk pregnancies has index pulsatility and resistance index in the superior mesenteric artery in the reference interface. The pregnancies with induced hypertension and also pregnancies with suspected fetal growth restriction were assessed as risk pregnancies. $12.5 \%$ of fetuses from the study group have increased resistance index in the superior mesenteric artery, and it was associated with poor postnatal adaptation (6). Mari's (1995) observations and reported result were probably influenced by the fact that gestational age of fetuses were not taken into consideration in the study.

The effect of gestational age on the parameters characterizing the resistance of vascular bed is confirmed. Until the 32nd gestational week, the resistance index and pulsatility index in the superior mesenteric artery do not change significantly, and later they increase. In the last trimester, the blood flow to visceral arteries decreases (7), while the blood flow to the cerebral circulation increases (8). It is probably caused by a gradual reduction in the placental perfusion.

The splanchnic circulation of eutrophic versus hypotrophic newborns is evaluated in several studies. The maximum speed of the blood flow in systole, the end-diastolic blood flow velocity and the time - average velocity of blood flow are lower in the superior mesenteric artery of hypotrophic preterm newborns than in eutrophic preterm newborns within the first seven days of life. At the same time, hypotrophic newborns have increased values of parameters characterizing the resistance of vascular bed in the superior mesenteric artery. These parameters rise during the first postnatal week, and the increase is lower in hypotrophic newborns (9). Similar conclusions are reported in the study performed by Martinussen, (1996) (10). These claims are contradictory to the results of van Bel's study, (1990). According to van Bel et al., (1990) the peak systolic velocity increases in hypotroph- 
ic newborns without increasing the end-diastolic velocity and mean blood flow velocity in the superior mesenteric artery (11). Splanchnic circulation is influenced by numerous factors. The blood flow velocity in the superior mesenteric artery is reduced by birth asphyxia, patent ductus arteriosus, dopamin, dobutamin, indomethacin, caffein and umbilical arterial catheter (12, 13). Van Bel, (1990) and Martinussen, (1996) have not taken into consideration the impact of gestational age and the other mentioned factors, thus obtaining different results.

\section{EFFECT OF ENTERAL NUTRITION ON THE SPLANCHNIC CIRCULATION}

The splanchnic circulation is influenced by enteral feeding. Differences in blood flow velocity are caused by volume and type of enteral nutrition and also by feeding intervals. The maximum increase in the blood flow velocity in the superior mesenteric artery occurs 30 to 45 minutes after enteral feeding. The tissue oxygenation index of the splanchnic circulation is assessed by near-infrared spectroscopy (NIRS) in stable preterm newborns, and the index increases after enteral feeding. The tissue oxygenation index in cerebral circulation does not change after enteral feeding (14). The mean blood flow velocity in the superior mesenteric artery increases by $83 \%$ and end - diastolic velocity by $77 \%$ postprandially (10). Peak systolic velocity and end-diastolic velocity in the splanchnic circulation rise also after pacifier sucking. The resistance index decreases after milk feeding, but not after pacificier sucking. During postprandial measurements the parameters characterizing blood flow velocity were not influenced by pacifier sucking (15). The increase in blood flow velocity in the superior mesenteric artery after pacifier sucking may be a result of the response mediated by the nerve system - so called cephalic response. It is the same mechanism as the one increasing gastric fluids secretion in adults due to smell stimulation (16). Unlike in eutrophic newborns and in the hypotrophic newborns without prenatal hemodynamic disturbances, the blood flow velocity does not increase and the pulsatility index does not decrease after the first enteral feeding in the hypotrophic newborns with prenatal hemodynamic disturbances.

\section{INTOLERANCE OF ENTERAL FEEDING AND NECROTIZING ENTEROCOLITIS}

Both, the intolerance of enteral feeding and necrotizing enterocolitis (NEC), occur more often in hypotrophic newborns than in eutrophic infants. Necrotizing enterocolitis is the most common gastrointestinal surgical emergency in neonates $(17,18)$. NEC is characterized by the damage to the mucosal barrier in the bowel, inflammation caused by pathogenic microorganism, and necrosis of the intestinal wall $(19,20)$. The diseases, which lead to reduced blood flow in the intestine and increase its metabolic activity, possibly causing bowel ischemia, are generally considered being other risk factors (21). Hemodynamic disturbance that occurs in hypotrophic fetuses often persists after the birth. It leads to increased blood flow to the cerebral circulation and to an increased vascular resistance in the descending aorta. The combination of the fetal hypoxia and increased vascular resistance in the mesenteric circulation can cause hypoxic - ischemic injury to the intestinal mucosa. Prolonged exposure may impair the development of motoric and secretary functions of the small intestine, and promote the pathogenic bacteria and their overgrowth in the intestinal wall (22). Experimental animal studies have shown that hypoxia reduces the blood flow velocity in the intestinal vessels and oxygen delivery via adrenergic vasoconstriction. Reduction of blood flow velocity by $30 \%$ can be compensated by increased oxygen extraction, but enteral feeding reduces the ability to extract oxygen. Unlike in the hypotrophic preterm newborns without prenatal hemodynamic disturbances, the blood flow velocity is lower and the pulsatility index in the supe- 
rior mesenteric artery and coeliac artery is higher on the first day after birth in the preterm small for date newborns with prenatal hemodynamic disturbances. Eutrophic newborns have a higher blood flow velocity compared with hypotrophic newborns irrespective of the presence of hemodynamic disturbance. There are no differences in the blood flow velocity in the anterior cerebral artery at that time. The increase in the blood flow velocity in the anterior cerebral artery of the small for date newborns with prenatal hemodynamic disturbance occurs on the 3rd day after the birth, probably as a result of postanoxic hyperperfusion (23). There is a reduced regional oxygen saturation in the splanchnic circulation assessed by near - infrared spectroscopy in preterm newborns with intolerance of enteral feeding. Persistent low oxygen saturation values had been reported in newborns, in whom necrotizing enterocolitis developed subsequently (24). Doppler studies have confirmed an association between a significant increase in the blood flow velocity in the superior mesenteric artery, and a lower incidence of intestinal dysmotility and better tolerance of enteral feeding in the first week after the birth $(25,26)$. An increased risk for developing necrotizing enterocolitis is described in neonates with a higher resistance index and absent end - diastolic velocity in the superior mesenteric artery during the first day after the birth $(27,28)$. Pezzati et al., (2004) consider the mean blood flow velocity of less than $0.38 \mathrm{~m} / \mathrm{s}$ in 30 minutes after the first feeding as the most sensitive predictor of intolerance of enteral feeding. Feeding of these newborns begins at 24 hours after the birth or later (29). Similarly, Fang et al., (2001) observed an increased risk for enteral feeding intolerance, if the mean blood flow velocity has not increased more than by $17 \% 60$ minutes after the first feeding (26). Hypotrophic infants have more often abdominal problems and delayed onset of tolerance of enteral feeding, compared with eutrophic newborns. Abdominal signs manifest within 3 days after the birth, whereas in eutrophic newborns they usually occur within 5 postnatal days (25). Moreover, meconium passage is delayed and abdominal distension occurs more frequently in this group of infants. The small for date newborns require parenteral nutrition for longer time and the interruption of enteral feeding occurs more often (29).

\section{CONCLUSION}

Literary data confirm the increased risk of intolerance of enteral feeding and necrotizing enterocolitis in hypotrophic newborns. Especially preterm small for date newborns with reverse or absent end-diastolic velocity in the umbilical artery are at risk for the mentioned conditions $(30,31)$. On the other hand, enteral nutrition is essential for intestinal maturation and growth, it increases blood flow in the splanchnic circulation, stimulates intestinal motility, and induces the release of trophic factors (32). It also reduces the need for parenteral nutrition, and thus reduces the risk of associated complications.

Doppler sonography is an excellent method evaluating of neonatal splanchnic circulation. The method is easily accessible, bed-side, noninvasive and painless. The research that is being realized at the Clinic of Neonatology of University Hospital in Martin and Jessenius Medical Faculty of Comenius University, has a goal to add knowledge on neonatal Doppler ultrasonography. Hopefully, measuring the parameters characterizing blood flow will help to identify a newborn at risk as early as possible and to eliminate incidence of enteral feeding intolerance and of necrotizing enterocolitis by means of planning an individual start of enteral feeding. 


\section{REFERENCES}

1. Mandruzzato G. Intrauterine growth restriction (IUGR): Guidelines for definition, recognition and management. Arch Perinat Med 2008; 14 (4): 7 - 8.

2. Kolarovszká H. Hodnotenie prietoku krvi obličkami hypotrofických novorodencov pomocou dopplerovskej sonografie, Martin, 2005, PhD thesis on Jessenius medical faculty of Comenius University in Martin.

3. Višňovský J. Vyšetrenie cirkulácie v pôrodníctve. Martin: Osveta; 2002.

4. Hernandez - Andrade E, Figueroa - Diesel H, Jansson T, Rangel - Nava H, Gratacos E. Changes in regional fetal cerebral blood flow perfusion in relation to hemodynamic deterioration in severely growth restricted fetuses. Ultrasound Obstet Gynecol 2008; 32: $71-76$.

5. Mari G, Abuhamad AZ, Uerpairojkit B, Martinez E, Copel JA. Blood flow velocity waveforms of the abdominal arteries in appropriate - and small - for - gestational - age fetuses. Ultrasound Obstet Gynecol 1995; 6: $15-18$.

6. Korszun P, Dubiel M, Breborowicz G, Danska A, Gudmudsson S. Fetal superior mesenteric blood flow velocimetry in normal and high - risk pregnancy. J Perinat Med 2002; 30: 235 - 241.

7. Dubiel M, Kozber H, Debniak B, Breborowicz GH, Marsál K, Gudmudsson S. Fetal and placental power Doppler imaging in normal and high - risk pregnancy. Eur J Ultrasound 1999; 9: 223.

8. Gudmudsson S, Dubiel M, Kozber H, Ropacka M, Breborowicz GH, Marsál K. Power Doppler signals of fetal brain and lung blood flow in normal and high - risk pregancies. Prenat Neonatal Med 1999; 4: 282.

9. Maruyama K, Koizumi T. Superior mesenteric artery blood flow velocity in small for gestational age infants of very low birth weight during the early neonatal period. J Perinat Med 2001; 29: 64 - 70.

10. Martinussen M, Brubakk A - M, Vik T, Yao AC. Mesenteric blood flow velocity and its relation to transitional circulatory adaptation in appropriate for gestational age preterm infants. Pediatr Res 1996; 39 (2): $275-280$.

11. Van Bel F, Van Zoeren D, Schipper J, Guit GL, Baan J. Effect of indomethacin on superior mesenteric artery blood flow velocity in preterm infants. J Pediatr 1990; 116: 965.

12. Ilves P, Lintrop M, Talvik I, Maipuu L. Changes in cerebral and visceral blood flow velocities in asphyxiated term neonates with hypoxic - ischemic encephalopathy. J Ultrasound Med 2009; 28: 1471 - 1480.

13. Hoodbhoy SA, Cutting HA, Seddon JA, Campbell ME. Cerebral and splanchnic hemodynamics after duct ligation in very low birth weight infants. J Pediatr 2009; 154: $196-200$.

14. Dave V, Brion LP, Campbell DE, Scheiner M, Raab C, Nafday SM. Splanchnic tissue oxygenation, but not brain tissue oxygenation, increases after feeds in stable preterm neonates tolerating full bolus orogastric feeding. $\mathrm{J}$ Perinatol 2009; 29: $231-218$.

15. Huang CHF, Tsai MCH, CHu CHH, Lee MY, Shih YL, CHeng SN. The influence of pacificier sucking on mesenteric blood flow in infants. Clin Pediatr 2003; 42: $543-546$.

16. Ganong WF. Regulation of gastrointestinal function. In : Ganong WF. Review of Medical Physiology. New York: McGraw - Hill; 1999. p. 459 - 491.

17. Moss RL, Kalish LA, Duggan C, Johnston P, Brandt ML, Dunn JC, Ehrenkranz RA, Jaksic T, Nobuhara K, Simpson BJ et al. Clinical parameters do not adequately predict outcome in necrotizing enterocolitis: a multi institutional study. J Perinatol 2008; 28: 665 - 674.

18. Srinivasan PS, Brandler MD, D' souza A. Necrotizing enterocolitis. Clin Perinatol 2008; 35: 251 - 272.

19. Matašova K. Neonatológia. Bratislava: Vydavatelstvo UK; 2012.

20. Grave GD, Nelson SA, Walker WA, Moss RL, Dvorak B, Hamilton FA, Higgins R, Raju TN. New therapies and preventive approaches for necrotizing enterocolitis : report of a research planning workshop. Pediatr Res 2007; 62: $510-514$.

21. Nankervis CA, Giannone PJ, Reber KM. The neonatal intestinal vasculature: contributing factors to necrotizing enterocolitis. Semin Perinatol 2008; 32: 83 - 91.

22. Dorling J, Kempley S, Leaf A. Feeding growth restricted preterm infants with abnormal antenatal Doppler results. Arch Dis Child Fetal Neonatal Ed 2005; 90: F359 - F363.

23. Kempley ST, Gamsu HR, Vyas S, Nicolaides K. Effect of intrauterine growth retardation on postnatal visceral and cerebral blood flow velocity. Arch Dis Child 1991; 66: 1115 - 1118.

24. Cortez J, Gupta M, Amaran A, Pizzino J, Sawhney M, Sood BG. Noninvasive evaluation of splanchnic tissue oxygenation using near - infrared spectroscopy in preterm neonates. J Matern Fetal Neonatal Med 2011; 24 (4): $574-582$.

25. Robel -Tillig E, Vogtmann C, Bennek J. Prenatal hemodynamic disturbances - patophysiological backround of intestinal motility disturbances in small for gestational age infants. J Pediatr Surg 2002; 12: 175 - 179.

26. Fang S, Kempley ST, Gamsu HR. Prediction of early tolerance to enteral feeding in preterm infants by measurements of superior mesenteric artery blood flow velocity. Arch Dis Child Fetal Neonatal Ed 2001; 85: $42-45$.

27. Murdoch EM, Sinha AK, Shanmugalingam T, Smith GCS, Kempley ST. Doppler flow velocimetry in the superior mesenteric artery on the first day of life in preterm infants and the risk of neonatal necrotizing enterocolitis. Pediatrics 2006; 118: 1999 - 2003.

28. Bora R, Mukhopadhyay K, Saxena AK, Jain V, Narang A. Prediction of feed intolerance and necrotizing enterocolitis in neonates with absent end diastolic flow in umbilical artery and the correlation of feed intolerance with postnatal superior mesenteric artery flow. J Matern Fetal Neonatal Med 2009; 22: 1092 - 1096. 
29. Pezzati M, Dani C, Tronchnin M, Filippi L, Rossi S, Rubaltelli FF. Prediction of early tolerance to enteral feeding by measurement of superior mesenteric artery blood flow velocity: appropriate - versus small - for - gestational - age. Acta Paediatr 2004; 93: 797 - 802.

30. Bhatt AB, Tank PD, Barmade KB, Damania KR. Abnormal Doppler flow velocimetry in the growth restricted foetus as a predictor for necrotizing enterocolitis. JPGM 2002; 48 (3): 182 - 185.

31. Baschat AA, Gembruch U, Reiss I, Gortner L, Weiner CP, Harman CR. Relationship between arterial and venous Doppler and perinatal outcome in fetal growth restriction. Ultrasound Obsted Gynecol 2000; 16: $407-413$.

32. Reber KM, Nankervis CA, Nowicki PT. Newborn intestinal circulation: physiology and pathophysiology. Clin Perinatol 2002; 29: 23 - 39 .

\section{Acknowledgment:}

The work was supported by Grant of UK 101/2012 and the project Center of Excellence of Perinatology Research, project co - financed from EU sources (Code 262201200 16).

Received: September, 15, 2012

Accepted: November, 3, 2012 